\title{
VALIDATION OF NEW SATELLITE AEROSOL OPTICAL DEPTH RETRIEVAL ALGORITHM USING RAMAN LIDAR OBSERVATIONS AT RADIATIVE TRANSFER LABORATORY IN WARSAW
}

\author{
Olga Zawadzka $^{1 *}$, Iwona S. Stachlewska ${ }^{1}$, Krzysztof M. Markowicz ${ }^{1}$, Anca Nemuc ${ }^{2}$, Kerstin Stebel ${ }^{3}$ \\ ${ }^{I}$ University of Warsaw, Faculty of Physics, Institute of Geophysics, Warsaw, Poland, \\ zawadzka@igf.fuw.edu.pl \\ ${ }^{2}$ Institute of Optoelectronic Research, Magurele, Romania \\ ${ }^{3}$ Norwegian Institute for Air Research, Kjeller, Norway
}

\begin{abstract}
During an exceptionally warm September of 2016, the unique, stable weather conditions over Poland allowed for an extensive testing of the new algorithm developed to improve the Meteosat Second Generation (MSG) Spinning Enhanced Visible and Infrared Imager (SEVIRI) aerosol optical depth (AOD) retrieval. The development was conducted in the frame of the ESA-ESRIN SAMIRA project. The new AOD algorithm aims at providing the aerosol optical depth maps over the territory of Poland with a high temporal resolution of 15 minutes. It was tested on the data set obtained between 11-16 September 2016, during which a day of relatively clean atmospheric background related to an Arctic airmass inflow was surrounded by a few days with well increased aerosol load of different origin. On the clean reference day, for estimating surface reflectance the AOD forecast available on-line via the Copernicus Atmosphere Monitoring Service (CAMS) was used. The obtained AOD maps were validated against AODs available within the Poland-AOD and AERONET networks, and with AOD values obtained from the PollyXT-UW lidar. of the University of Warsaw (UW).
\end{abstract}

\section{INTRODUCTION}

Despite considerable improvements in the past decades, Europe is still far from achieving levels of air quality that do not pose unacceptable hazards to humans and the environment. Inhabitants in urban areas still can experience significant health problems due to air pollution. Research on the air pollution issue on regional scale, is presently carried out in the frame of ESAESRIN founded project entitled SAtellite based Monitoring Initiative for Regional Air quality
(SAMIRA). The overall goal of the project is to improve regional and local air quality monitoring through synergistic use of data from present and upcoming satellite missions, traditionally used insitu air quality monitoring networks, and output from chemical transport models.

Through collaborative efforts of Poland, Romania, the Czech Republic, and Norway, countries confronted with different but pressing air quality problems, the SAMIRA aims at both to support national monitoring obligations and to generate novel research in this area. In SAMIRA, the most relevant pollutants are being addressed; $\mathrm{NO}_{2}, \mathrm{SO}_{2}$, particulate matter $\mathrm{PM}_{2.5}$ and $\mathrm{PM}_{10}$, as well as Aerosol Optical Depth (AOD). The latter can be directly retrieved or indirectly estimated from existing satellites sensors. The satellite retrieval of aerosol properties over land is challenging mainly due to the high surface reflectance, its temporal variability, and spatial inhomogeneity, but also due to anisotropic bi-directional reflectance of land surfaces, which induces higher uncertainties of retrieved parameters. For this paper we choose to exploit the geostationary SEVIRI/MSG sensor [1], as for air quality quasi-continuous, high temporal and spatial resolution monitoring is a necessity. The optimal interpolation approach to retrieve AOD from the SEVIRI data, initially developed by [2], was elaborated for the further improvement. A new version of algorithm was developed and tested on the data set collected between 11-16 September 2016. The obtained AOD values were validated against the next generation PollyXT-UW lidar in Warsaw [3,4], as well as by using the AOD data sets available within the Polish aerosol network Poland-AOD (http://www.polandaod.pl/) and AERONET (https://aeronet.gsfc.nasa.gov/). 


\section{METHODOLOGY}

The modified AOD retrieval algorithm is fed with the high temporal and spatial resolution data from SEVIRI channel $1(635 \mathrm{~nm})$ and it allows for retrieving $\mathrm{AOD}$ at a spatial resolution of about $5 \times 5 \mathrm{~km}$ at a frequency of $15 \mathrm{~min}$. The most important parameter for the retrieval process is the surface reflectance. The surface properties are estimated during relatively cloud free reference days (cloud cover $<1 / 8)$ with a low AOD $(<0.1$ at $500 \mathrm{~nm}$ ), based on the Top-Of-Atmosphere reflectance measured by the SEVIRI detector. Even if the AOD is low, elimination of influence of atmospheric components, in particular atmospheric aerosols, on the reflectance measured by satellite is still essential. By applying the optimal interpolation method [5] and the additional ground based sources of AOD data the uncertainties related to the aerosol background estimation errors can be reduced to improve the AOD retrieval. For more details of the retrieval scheme refer to [2]. The main changes introduced in the new algorithm include following: I) CAMS AOD forecast data [6] are used as an AOD background information for a reference day; II) all Polish ground-based stations with a continuous AOD measurements are implemented in the code; and III) cloud screening process was improved. Favourable conditions in September 2016 allowed for tests and validation of the new version of algorithm.

Observations and calculations for two 2 days: $11^{\text {th }}$ and $15^{\text {th }}$ September are discussed. On these days, the PollyXT-UW lidar observations were taken at the Radiative Transfer Laboratory (RT-Lab) of the Institute of Geophysics, Faculty of Physics, University of Warsaw (Poland). The RT-Lab site located at central Warsaw $\left(52.21^{\circ}, \mathrm{N} 20.98^{\circ} \mathrm{E}, 112\right.$ $\mathrm{m}$ a.s.1.) joined the EARLINET [7] in March 2015 , and is regularly contributing to the network activities. We use the 12-channel NeXT generation Polly XT system equipped with the photon-counting detection channels at 1064, 532, and $355 \mathrm{~nm}$ (elastic), 607 and $387 \mathrm{~nm}$ (N2 Raman), $407 \mathrm{~nm}$ (H2O Raman), 532 and $355 \mathrm{~nm}$ (elastic cross). Since April 2016, lidar is equipped additionally with the Near Range Aerosol Lidar receiver (NARLa) at 532 and $355 \mathrm{~nm}$ (elastic), 607 and $387 \mathrm{~nm}$ (N2 Raman), which significantly enhances lowermost range of lidar observations.

\section{RESULTS AND DISCUSSION}

On $11^{\text {th }}$ September, which was a day with well increased aerosol load captured, the backtrajectories calculated using the HYSPLIT model [8], indicated possible occurrence and even accumulation of local pollution over Warsaw due to heat wave conditions (Fig. 1). Results of the NAAPS model simulations [9] suggest that sulphates were significant part of aerosol load on that day (Fig. 2). On the contrary, $15^{\text {th }}$ September was characterized by significantly cleaner conditions, which were related to an Arctic airmass inflow. Thus, this day was chosen to be used as a reference day for estimating the surface properties. The application of algorithm on SEVIRI data on $11^{\text {th }}$ September provided the AOD maps over Poland with a temporal resolution of 15 minutes. An example of such a map is given in Fig. 3. The obtained AOD-SEVIRI values, (pixel regarded as representative for the Warsaw EARLINET site) were validated against the PollyXT-UW lidar. The lidar-derived AOD at $532 \mathrm{~nm}$ was obtained from the extinction profiles. Additionally, the SEVIRI AOD data at $635 \mathrm{~nm}$ were compared with the MFR-7 shadow-band radiometer observations of AOD at $614 \mathrm{~nm}$, showing generally a sufficient agreement.

NOAA HYSPLIT MODEL

Backward trajectories ending at 0700 UTC 11 Sep 16 GFSG Meteorological Data

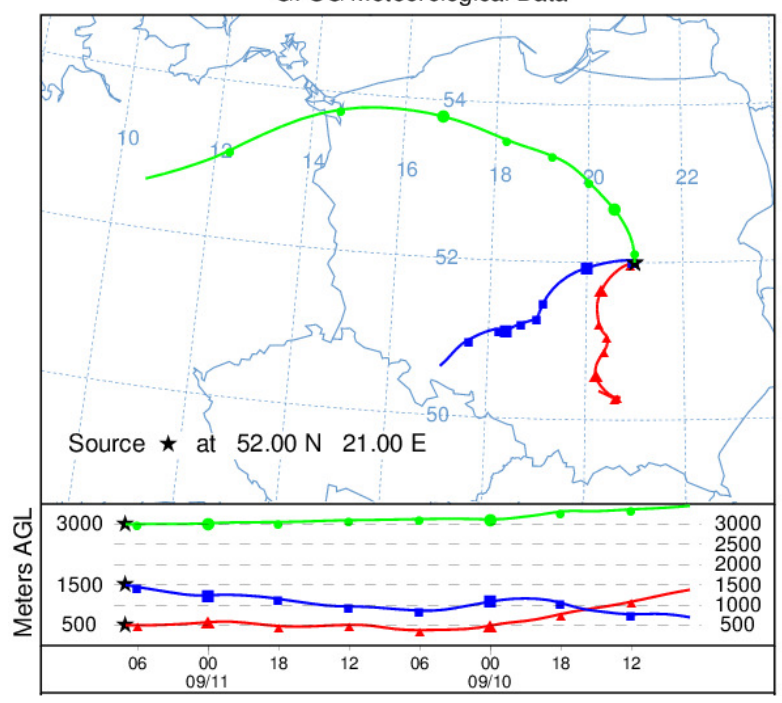

Figure 1 The HYSPLIT back-trajectories obtained for Warsaw at 7:00 UTC for $11^{\text {th }}$ September. The model was run for $48 \mathrm{~h}$ with meteorological data from the Global Data Assimilation System (GDAS). 


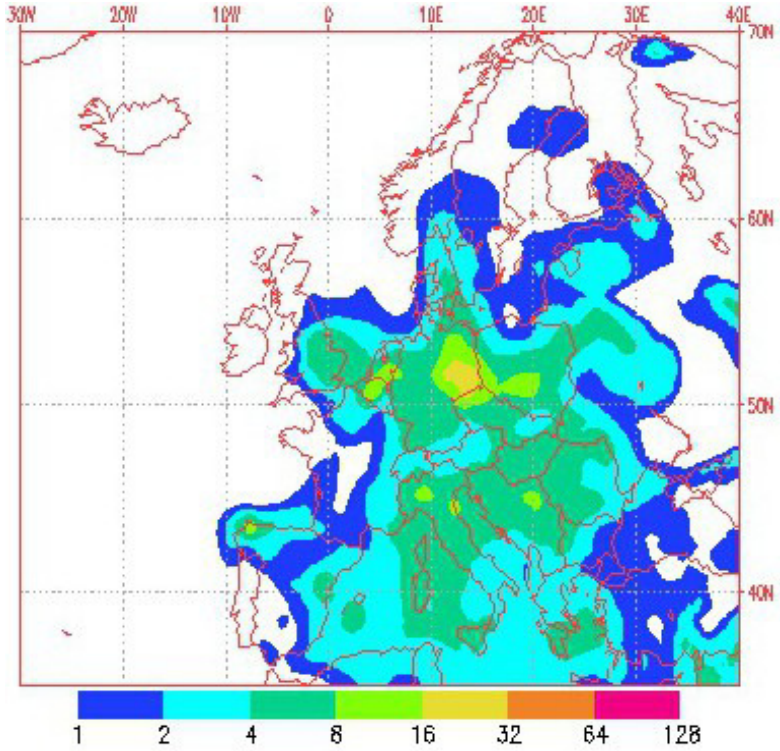

Figure 2 Sulfate surface concentration $\left(\mu \mathrm{g} / \mathrm{m}^{3}\right)$ on 11 September 2016, obtained from Navy Aerosol Analysis and Prediction System (NAAPS).

The AOD map (Fig. 3) at 635nm was calculated for data acquired at 7:00 UTC on $11^{\text {th }}$ September 2016. Lack of data in northern and western areas of the map are due to the cloud cover. For pixel that covers Warsaw, the AOD SEVIRI for $15 \mathrm{~min}$ observations was 0.303 . At the same time the AOD measured by the MFR-7 at the RT-Lab in Warsaw equalled 0.391 at $615 \mathrm{~nm}$ and 0.52 at $500 \mathrm{~nm}$. In Figure 4, the daily evaluation of the range and background corrected lidar signal at $1064 \mathrm{~nm}$ on $11^{\text {th }}$ September 2016 is shown. The aerosol load is visible up to $3 \mathrm{~km}$, signatures of nocturnal and residual layers are pronounced. At 1-2, 12, and 13-14 UTC some clouds are captured.

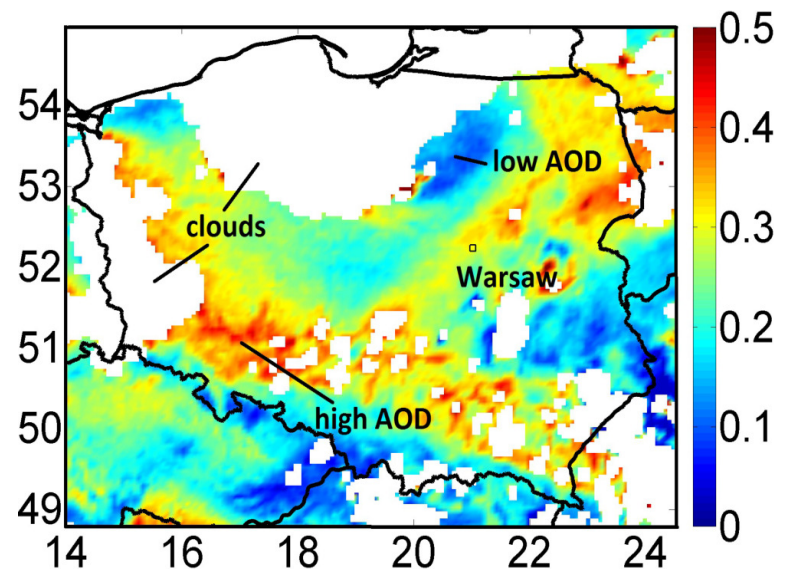

Figure 3 SEVIRI AOD at $635 \mathrm{~nm}$ calculated for $15 \mathrm{~min}$ at 7:00 UTC on 11 September 2016.
For the data collected at 7:00 UTC, the aerosol extinction and backscatter coefficient profiles at $355 \mathrm{~nm}$ and $532 \mathrm{~nm}$ were calculated using the classical Raman approach [10] for the $2 \mathrm{~h}$ average with 81 points running mean smoothing.

The extinction retrieval was possible down to $400 \mathrm{~m}$, as we used the NARLa module. The nearand far-range profiles were calculated separately and combined afterwards. The missing values were interpolated with a constant extinction value at $400 \mathrm{~m}$. The maximum value of the particle extinction coefficient at $532 \mathrm{~nm}$ of about $0.9 \mathrm{~km}^{-1}$ was obtained at about $2 \mathrm{~km}$. From the extinction profile the AOD of $0.113,0.469,0.545$ was obtained by integration up to 1,2 and $3 \mathrm{~km}$, respectively. The latter value, was used for the comparison with the AOD-SEVIRI map pixel value for Warsaw.

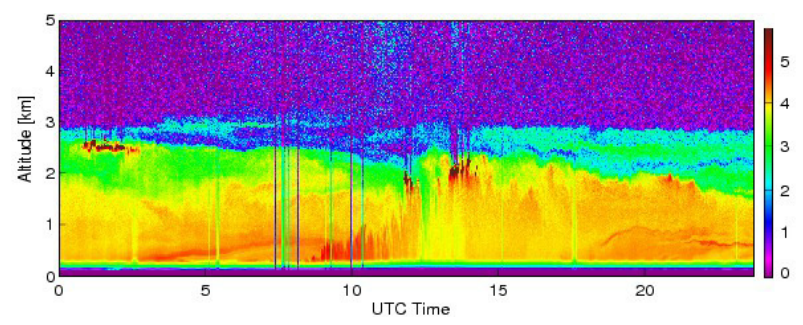

Figure 4 Lidar range corrected signal at $1064 \mathrm{~nm}$ on 11 September 2016. Measurements were taken with the PollyXT-UW lidar at the Radiative Transfer Laboratory RT-Lab in Warsaw.

The AOD SEVIRI in Warsaw was lower than the AOD obtained both from lidar and radiometric observations, although we keep in mind that this the data are not directly comparable. First of all, because the difference in the compared ADOwavelength have to be taken into account. Secondly, because ground-based measurements are representative for a single point, while the SEVIRI data cover area of $5 \times 5 \mathrm{~km}$, and thus the $\mathrm{AOD}$ is in fact a mean value for the whole pixel.

In the presented cases the obtained SEVIRI AOD was slightly underestimated in comparison to the lidar and radiometric observations. Such underestimation could be caused by an inaccurate estimation of the surface properties during the reference day ( $15^{\text {th }}$ September). Analysis of lidar measurements allows to confirm that indeed this day was not a perfectly clean one (not a typical clean background for Warsaw [11]). Although the maximum value of the lidar particle extinction 
coefficient at $532 \mathrm{~nm}$ was nearly 10 times lower than the maximum value measured on $11^{\text {th }}$ September, a closer look at the lidar derived intensive and extensive properties indicates an existence of small particles with Ångström Exponent (532/355) strongly oscillating around 2 within the ground and $2.4 \mathrm{~km}$. This is accompanied with a very low tinear polarization ratio of $0.018 \pm 0.04$ at $532 \mathrm{~nm}$, lidar ratio of $50 \pm 12$ sr at $532 \mathrm{~nm}$, and the AOD at $532 \mathrm{~nm}$ of $0.328 \pm 0.015$ (obtained from the ground up to 3 $\mathrm{km}$ ). Thus, we interpret the lidar data set obtained on $15^{\text {th }}$ September 2017 as typical for background conditions contaminated with a slight urban anthropogenic origin pollution.

\section{CONCLUSIONS}

Presented in this paper AOD SEVIRI retrieval algorithm gives opportunity for quasi-continuous measurements providing AOD maps over Poland with high temporary resolution up to $15 \mathrm{~min}$. Regarding the observed AOD differences between various sensors, the valuable information obtained from the lidar allowed for successful validation of the algorithm, as potential areas of problems were identified. Further algorithm adjustments will be undertaken, such as development of an additional procedure for a more appropriate choice of the reference day. The lidar validation of the SEVIRI pixel AOD for Warsaw data will be continued. We will also try to determine any relations of specific weather conditions to aerosol properties [11].

\section{ACKNOWLEDGEMENTS}

The scientific work presented in this paper was performed in the frame of the SAtellite based Monitoring Initiative for Regional Air quality (SAMIRA) funded by the ESA-ESRIN Contract 4000117393/16/I-NB and the Technical assistance for Polish Radar and Lidar Mobile Observation System (POLIMOS) funded by the ESA-ESTEC Contract 4000119961/16/NL/FF/mg.

The development of the PollyXT-UW lidar was financed by the Polish Foundation of Science and Technology FNTP-No.519/FNITP/115/2010.

The lidar was developed in collaboration of the University of Warsaw (IGFUW) with the Institute of Tropospheric Research (TROPOS). We would like to acknowledge colleagues from the PollyXT development group of Dr. Dietrich Althausen.

\section{References}

[1] Aminou, D.M., 2002: MSG's SEVIRI Instrument. ESA bulletin 111, 15-17.

[2] Zawadzka, O. and K. Markowicz, 2014: Retrieval of Aerosol Optical Depth from Optimal Interpolation Approach Applied to SEVIRI Data, Remote Sens. 6, 7182-7211.

[3] Engelmann R., et al.: The automated multiwavelength Raman polarization and water-vapor lidar PollyXT: the neXT generation, Atmos. Meas. Tech. 9, 1767-1784.

[4] Althausen D., et al.: Polly NET - a network of multiwavelength polarization Raman lidars. Proc. SPIE Lidar Technologies, Techniques, and Measurements for Atmospheric Remote Sensing IX, paper no 8894-17, pp.10, SPIE Remote sensing, 23-26 September 2013, Dresden, Germany, (88940I, October 22, 2013).

[5] Rodgers, C., 2000: Inverse Methods for Atmospheric Sounding; Theory and Practice, Series on Atmospheric, Oceanic and Planetary Physics; vol. 2, World Scientific: Singapore.

[6] CAMS - Copernicus Atmosphere Monitoring Service (http://atmosphere.copernicus.eu/).

[7] Pappalardo, G., et al., 2014: EARLINET towards an advanced sustainable European aerosol lidar network, Atmos. Meas. Tech. 7, 2389-2409.

[8] Draxler, R. R., Rolph, G. D., 2010: HYSPLIT (HYbrid Single-Particle Lagrangian Integrated Trajectory). Model access via READY Website (ready.arl.noaa.gov/HYSPLIT.php). NOAA Air Resources Laboratory, Silver Spring, MD.

[9] Navy Aerosol Analysis and Prediction System (NAAPS): http://www.nrlmry.navy.mil/aerosol/ (accessed on $9^{\text {th }}$ January 2017).

[10] Baars H., et al.: An overview of the first decade of PollyNET: an emerging network of automated Raman-polarization lidars for continuous aerosol profiling, Atmos. Chem. Phys., 16, 5111-5137, 2016.

[11] Stachlewska I.S., Zawadzka O., Engelmann R., 2017: Effect of Heat Wave Conditions on Aerosol Optical Properties Derived from Satellite and Ground-Based Remote Sensing over Poland, Remote Sensing, vol. 9 (11) pp. art. 1199 10.3390/rs9111199 